\title{
Effect of Combination Therapy With Simvastatin and Carvedilol in Patients With Left Ventricular Dysfunction Complicated With Acute Myocardial Infarction Who Underwent Percutaneous Coronary Intervention
}

\author{
Young Joon Hong, MD; Myung Ho Jeong, MD; Sun Ho Hwang, MD; Nam Sik Yun, MD; \\ Sang Rok Lee, MD; Seo Na Hong, MD; Kye Hun Kim, MD; Hyung Wook Park, MD; \\ Ju Han Kim, MD; Youngkeun Ahn, MD; Jeong Gwan Cho, MD; \\ Jong Chun Park, MD; Jung Chaee Kang, MD
}

\begin{abstract}
Background This study assessed the effects of combination therapy with simvastatin and carvedilol on clinical outcome in patients with left ventricular (LV) dysfunction after acute myocardial infarction (AMI).

Methods and Results The study retrospectively analyzed the data from 672 patients with LV dysfunction [LV ejection fraction (LVEF) $<40 \%$ ] complicated with AMI who underwent percutaneous coronary intervention (PCI). The patients were divided into 4 treatment groups: combination group $(n=160)$, simvastatin only group $(n=216)$, carvedilol only group $(n=242)$, neither treatment group $(n=54)$. At 6 months after PCI, the LVEF had improved most significantly in the combination group. During 1-year follow-up, cardiac death occurred most frequently in the neither treatment group compared with the other 3 groups (combination: $4 \%$, simvastatin alone: $7 \%$, carvedilol alone: $8 \%$, neither: $17 \%, \mathrm{p}<0.001$ between neither treatment and other 3 groups). The results on major adverse cardiovascular events (MACE) showed that the combination of simvastatin and carvedilol was associated with a relative risk reduction of $53 \%(\mathrm{p}<0.001)$, treatment with simvastatin alone with a relative risk reduction of $44 \%(\mathrm{p}=0.001)$, and carvedilol alone with a relative risk reduction of $40 \%(\mathrm{p}=0.003)$ compared with neither treatment. The independent predictors of 1-year MACE were neither treatment, elevated high sensitivity C-reactive protein $(\geq 0.5 \mathrm{mg} / \mathrm{dl})$, and old age ( $>70$ years).

Conclusion Combination therapy with simvastatin and carvedilol had a positive impact on the endpoints of cardiovascular death and MACE and seems to have an additive beneficial effect on these endpoints in patients with LV dysfunction complicated with AMI who underwent PCI. (Circ J 2006; 70: 1269-1274)
\end{abstract}

Key Words: Adrenergic $\beta$-antagonists; Coronary artery disease; Heart failure; Statins

$A$ Ithough mortality from coronary artery disease (CAD) is declining, the incidence of associated heart failure (HF) is rising! Despite the effectiveness of lipid-lowering therapy and $\beta$-blockers in improving cardiovascular outcomes, many studies have demonstrated low treatment rates in patients with ischemic HF?

Therapy with hydroxymethylglutaryl coenzyme A reductase inhibitors (statins) lowers the mortality and morbidity of CAD and other atherosclerotic vascular disease, as evidenced by multiple large-scale clinical trials? ${ }^{3} 6$ Statins show potential therapeutic benefits to patients with ischemic or non-ischemic HF, irrespective of lipid levels? On the other hand, some authors report potential adverse effects of statins in HF, and a relationship between low serum cholesterol level and worse clinical outcomes in HF. ${ }^{9}$

(Received May 15, 2006; revised manuscript received July 21, 2006; accepted August 4, 2006)

The Heart Center of Chonnam National University Hospital, Chonnam National University Research Institute of Medical Sciences, Gwangju, Korea

Mailing address: Myung Ho Jeong, MD, PhD, FACC, FAHA, FESC, FSCAI, Professor, Chief of Cardiovascular Medicine, Director of Cardiac Catheterization Laboratory, The Heart Center of Chonnam National University Hospital, 8 Hak-dong, Dong-gu, Gwangju 501-

757, Korea. E-mail: myungho@ chollian.net
Carvedilol is known not only as a vasodilating $\beta$-andablocker, but also as an antioxidant, and it may reduce the oxidative stress level in the human failing myocardium! 10 Previous studies have demonstrated that carvedilol prolonged survival and ameliorated the morbidity of patients with severe HF!1-13

However, little data are available about the effect of combining statin and $\beta$-blocker therapies on clinical outcome in patients with left ventricular (LV) dysfunction complicated with acute myocardial infarction (AMI) who undergo percutanous coronary intervention (PCI). We hypothesized that this combination would be associated with lower allcause mortality and morbidity in such patients.

\section{Methods}

\section{Study Population}

This was a single-center, retrospective, non-randomized study. We studied 672 patients with LV dysfunction [LV ejection fraction (LVEF) <40\%] complicated with AMI who underwent PCI between January 2000 and June 2004. Patients who underwent PCI for the treatment of AMI were included regardless of the type of PCI procedure such as primary, rescue, or elective. The patients were divided into 4 treatment groups: combination group $(n=160,61 \pm 11$ 
Table 1 Baseline Clinical Characteristics

\begin{tabular}{|c|c|c|c|c|}
\hline & \multicolumn{4}{|c|}{ Simvastatin use } \\
\hline & \multicolumn{2}{|c|}{$\begin{array}{c}(+) \\
\text { Carvedilol use }\end{array}$} & \multicolumn{2}{|c|}{$\begin{array}{c}(-) \\
\text { Carvedilol use }\end{array}$} \\
\hline & $\begin{array}{c}(+) \\
(n=160)\end{array}$ & $\begin{array}{c}(-) \\
(n=216)\end{array}$ & $\begin{array}{c}(+) \\
(n=242)\end{array}$ & $\begin{array}{c}(-) \\
(n=54)\end{array}$ \\
\hline Age (years) & $61 \pm 11$ & $62 \pm 10$ & $63 \pm 10$ & $65 \pm 12 *$ \\
\hline Men & $112(70 \%)$ & $156(72 \%)$ & $165(68 \%)$ & $40(74 \%)$ \\
\hline Hypertension & $25(40 \%)$ & $76(35 \%)$ & $92(38 \%)$ & $20(37 \%)$ \\
\hline Diabetes mellitus & $51(32 \%)$ & $65(30 \%)$ & $68(28 \%)$ & $14(26 \%)$ \\
\hline Smoker & $77(48 \%)$ & $112(52 \%)$ & $128(53 \%)$ & $26(49 \%)$ \\
\hline Hyperlipidemia & $94(59 \%)^{\dagger}$ & $134(62 \%)^{\dagger}$ & $97(40 \%)$ & $18(33 \%)$ \\
\hline Prior myocardial infarction & $5(3 \%)$ & $4(2 \%)$ & $6(2 \%)$ & $1(2 \%)$ \\
\hline Prior percutaneous coronary intervention & $7(4 \%)$ & $7(3 \%)$ & $9(4 \%)$ & $2(4 \%)$ \\
\hline Pain to door time ( $\mathrm{min}$ ) & $209 \pm 168$ & $219 \pm 176$ & $226 \pm 178$ & $209 \pm 166$ \\
\hline Pain to balloon time (min) & $422 \pm 398$ & $429 \pm 331$ & $431 \pm 338$ & $419 \pm 306$ \\
\hline Ejection fraction $(\%)$ & $32 \pm 8$ & $30 \pm 9$ & $34 \pm 5$ & $29 \pm 9$ \\
\hline Multivessel disease & $110(69 \%)$ & $152(70 \%)$ & $162(67 \%)$ & $38(70 \%)$ \\
\hline Atrial fibrillation & $16(10 \%)$ & $17(8 \%)$ & $17(7 \%)$ & $6(11 \%)$ \\
\hline \multicolumn{5}{|l|}{ Simvastatin dose (mg) } \\
\hline 20 & $99(62 \%)$ & $138(64 \%)$ & & \\
\hline 40 & $61(38 \%)$ & $78(36 \%)$ & & \\
\hline \multicolumn{5}{|l|}{ Carvedilol dose $(\mathrm{mg})$} \\
\hline 6.25 & $96(60 \%)$ & & $150(62 \%)$ & \\
\hline 12.5 & $56(35 \%)$ & & $82(34 \%)$ & \\
\hline 25 & $8(5 \%)$ & & $10(4 \%)$ & \\
\hline
\end{tabular}

${ }^{*} p<0.05$ compared with simvastatin-treated group. ${ }^{\dagger} p<0.05$ compared with non-simvastatin-treated group.

years, men $70 \%)$, simvastatin only group $(n=216,62 \pm 10$ years, men $72 \%)$, carvedilol only group $(n=242,63 \pm 10$ years, men $68 \%)$, neither treatment group $(n=54,65 \pm 12$ years, men $74 \%$ ). Patients with supine systolic arterial pressure $<90 \mathrm{mmHg}$ at admission, hemodynamically significant stenotic valvular heart disease, and hemodynamically significant dysrhythmia were excluded. Bedside echocardiography was performed for all patients before PCI or shortly after PCI and the LVEF was measured using the modified Simpson's method.

\section{Medications}

In the simvastatin group, the daily dose was 20 or $40 \mathrm{mg}$ and was usually started immediately after PCI. In the carvedilol group, the daily dose was $6.25,12.5$ or $25 \mathrm{mg}$ and was also usually started immediately after PCI. After PCI, all patients received aspirin ( $100 \mathrm{mg} /$ day, indefinitely) and ticlopidine $(250 \mathrm{mg}$ /day continued for at least 6 months $)$ or clopidogrel ( $75 \mathrm{mg} /$ day continued for at least 6 months). Medications were assessed at baseline and every 4 weeks during clinic examinations. Medications, exact dates of initiation and cessation, and doses were recorded.

\section{Laboratory Analysis}

In all patients, serum was collected before PCI for measuring lipid profiles and high-sensitivity C-reactive protein (hs-CRP) levels, fibrinogen, and white blood cells and each fraction. All laboratory values were measured after an overnight fast. The serum levels of total cholesterol, triglyceride, low-density lopoprotein (LDL)-cholesterol, and high-density lopoprotein-cholesterol were measured by standard enzymatic methods. hs-CRP was assessed by the immunoturbidimetric CRP-Latex (II) hs assay using a Olympus 5431 autoanalyzer (Olympus, Tokyo, Japan). The assay was performed according to the manufacturer's protocol and has been validated against the Dade-Behring method 14 Plasma fibrinogen level was quantified by means of the Clauss clotting assay (normal range: $150-450 \mathrm{mg} / \mathrm{dl}$ ). Total white blood cells and each fraction were measured with a Coulter Gen S (Beckman Coulter, Miami, FL, USA) automated hematology analyzer. Laboratory analysis was performed at admission and repeated at 6 months after PCI.

PCI

Coronary angiography was performed via the femoral arteries. All implanted stents were bare metal and implantation was performed in the case of suboptimal results for percutaneous balloon angioplasty, residual stenosis $>30 \%$, intimal dissection, or as a bail-out procedure! 15,16 Dalteparin was administered at 120 units $/ \mathrm{kg}$ body weight intravenously every $12 \mathrm{~h}$ or unfractionated heparin as an intravenous bolus (usually 5,000 units) followed by a continuous infusion at a dose adjusted according to the activated partial thromboplastin time.

\section{Clinical Follow-up}

After discharge, the patients were observed during 1-year follow-up for major adverse cardiovascular events (MACE), such as cardiac death, cerebrovascular accident, AMI, oir target lesion revascularization. Echocardiography was performed at admission and repeated at 6 months after PCI.

\section{Statistical Analysis}

The Statistical Package for Social Sciences (SPSS) for Windows, version 11.0 (Chicago, IL, USA) was used for all analyses. Results are presented as the mean value \pm SD for continuous variables and as the percentage of total patients for categorical variables. Differences in baseline characteristics were evaluated using t-tests and chi-square statistics. Survival curves were calculated by the Kaplan-Meier method. Logistic regression analysis was used to identify the independent predictors of MACE. We defined elevated CRP level as hs-CRP $\geq 0.5 \mathrm{mg} / \mathrm{dl}^{17-19}$ and old age as $>70$ years ${ }^{20} \mathrm{~A}$ p-value $<0.05$ was considered as significant. 
Table 2 Laboratory Findings

\begin{tabular}{|c|c|c|c|c|}
\hline & \multicolumn{4}{|c|}{ Simvastatin use } \\
\hline & \multicolumn{2}{|c|}{$\begin{array}{c}(+) \\
\text { Carvedilol use }\end{array}$} & \multicolumn{2}{|c|}{$\begin{array}{c}(-) \\
\text { Carvedilol use }\end{array}$} \\
\hline & $\begin{array}{c}(+) \\
(n=160)\end{array}$ & $\begin{array}{c}(-) \\
(n=216)\end{array}$ & $\begin{array}{c}(+) \\
(n=242)\end{array}$ & $\begin{array}{c}(-) \\
(n=54)\end{array}$ \\
\hline \multicolumn{5}{|l|}{ Baseline } \\
\hline Total cholesterol $(\mathrm{mg} / \mathrm{dl})$ & $201 \pm 40$ & $199 \pm 30$ & $189 \pm 43$ & $190 \pm 32$ \\
\hline Triglyceride $(\mathrm{mg} / \mathrm{dl})$ & $154 \pm 42$ & $150 \pm 36$ & $144 \pm 41$ & $140 \pm 32$ \\
\hline LDL-cholesterol $(\mathrm{mg} / \mathrm{dl})$ & $144 \pm 34$ & $146 \pm 28$ & $135 \pm 31$ & $133 \pm 28$ \\
\hline HDL-cholesterol ( $\mathrm{mg} / \mathrm{dl})$ & $42 \pm 9$ & $43 \pm 8$ & $44 \pm 10$ & $45 \pm 9$ \\
\hline High sensitivigy $C$-reactive protein $(\mathrm{mg} / \mathrm{dl})$ & $3.5 \pm 2.5$ & $3.4 \pm 2.4$ & $3.3 \pm 2.8$ & $3.0 \pm 2.5$ \\
\hline Fibrinogen $(\mathrm{mg} / \mathrm{dl})$ & $293 \pm 74$ & $281 \pm 89$ & $287 \pm 65$ & $281 \pm 80$ \\
\hline White blood cell $(\mathrm{mg} / \mathrm{dl})$ & $9,840 \pm 2,610$ & $9,870 \pm 3,040$ & $9,790 \pm 2,620$ & $9,780 \pm 3,010$ \\
\hline Monocyte $(\mathrm{mg} / \mathrm{dl})$ & $878 \pm 335$ & $870 \pm 280$ & $868 \pm 321$ & $860 \pm 270$ \\
\hline \multicolumn{5}{|l|}{ 6-month follow-up } \\
\hline Total cholesterol $(\mathrm{mg} / \mathrm{dl})$ & $159 \pm 38 *$ & $164 \pm 38 *$ & $178 \pm 33$ & $194 \pm 30$ \\
\hline Triglyceride $(\mathrm{mg} / \mathrm{dl})$ & $120 \pm 40^{*}$ & $124 \pm 30 *$ & $154 \pm 40$ & $150 \pm 30$ \\
\hline LDL-cholesterol $(\mathrm{mg} / \mathrm{dl})$ & $98 \pm 34 *$ & $100 \pm 32 *$ & $123 \pm 34$ & $128 \pm 38$ \\
\hline HDL-cholesterol $(\mathrm{mg} / \mathrm{dl})$ & $52 \pm 9 *$ & $49 \pm 10 *$ & $45 \pm 9$ & $43 \pm 8$ \\
\hline High sensitivigy $C$-reactive protein $(\mathrm{mg} / \mathrm{dl})$ & $0.6 \pm 2.5 *$ & $0.7 \pm 2.4 *$ & $0.9 \pm 1.5$ & $1.4 \pm 1.4$ \\
\hline Fibrinogen $(\mathrm{mg} / \mathrm{dl})$ & $255 \pm 74 *$ & $259 \pm 89 *$ & $275 \pm 74$ & $285 \pm 89$ \\
\hline White blood cell ( $\mathrm{mg} / \mathrm{dl})$ & $7,050 \pm 1,390^{*}$ & $7,200 \pm 3,020$ & $7,340 \pm 2,650$ & $7,400 \pm 3,040$ \\
\hline Monocyte $(\mathrm{mg} / \mathrm{dl})$ & $452 \pm 220^{*}$ & $456 \pm 218 *$ & $523 \pm 180$ & $580 \pm 178$ \\
\hline
\end{tabular}

${ }_{p}<0.05$ compared with neither treatment.

$L D L$, low-density lopoprotein; $H D L$, high-density lopoprotein.

\section{Results}

Baseline Clinical Characteristics (Table 1)

The mean age was highest in the neither treatment group and hyperlipidemia was more frequently observed in the simvastatin group than in the other treatment groups. The daily dose of simvastatin was $20 \mathrm{mg}$ in $62 \%$ and $64 \%$, and $40 \mathrm{mg}$ in $38 \%$ and $36 \%$ in the combination group and simvastatin only group, respectively. The daily dose of carvedilol was $6.25 \mathrm{mg}$ in $60 \%$ and $62 \%, 12.5 \mathrm{mg}$ in $35 \%$ and $34 \%$, and $25 \mathrm{mg}$ in $5 \%$ and $4 \%$ in the combination group and carvedilol only group, respectively. Other medications were not different among the 4 groups.

\section{Laboratory Findings}

Baseline and 6-month follow-up laboratory data are shown in Table 2. At 6 months after PCI, simvastatin treatment significantly decreased the LDL-cholesterol, hs-CRP and fibrinogen levels, and the monocyte count. The combination therapy showed the most significant improvement in lipid profiles and inflammatory markers.

\section{Systolic Function}

At 6 months after PCI, LVEF was most significantly improved in the combination group. From baseline to 6month follow-up, LVEF improved from $32 \pm 8 \%$ to $42 \pm 8 \%$ in the combination group, $30 \pm 9 \%$ to $38 \pm 7 \%$ in the simvastatin only group, $34 \pm 5 \%$ to $40 \pm 7 \%$ in the carvedilol only group, and $29 \pm 9 \%$ to the $32 \pm 6 \%$ in neither treatment group. Compared with baseline LVEF, it improved by $31 \%, 27 \%, 24 \%$, and $10 \%$, respectively, in the combination group, simvastatin only group, carvedilol only group, and neither treatment group at 6-month follow-up (Fig 1).

\section{MACE (Table 3)}

During the 1-year follow-up, 50 patients died, 11 patients had a cerebrovascular accident, 29 patients had a re-infarction and target lesion revascularization was performed in 136 patients. Combination therapy was associated with a

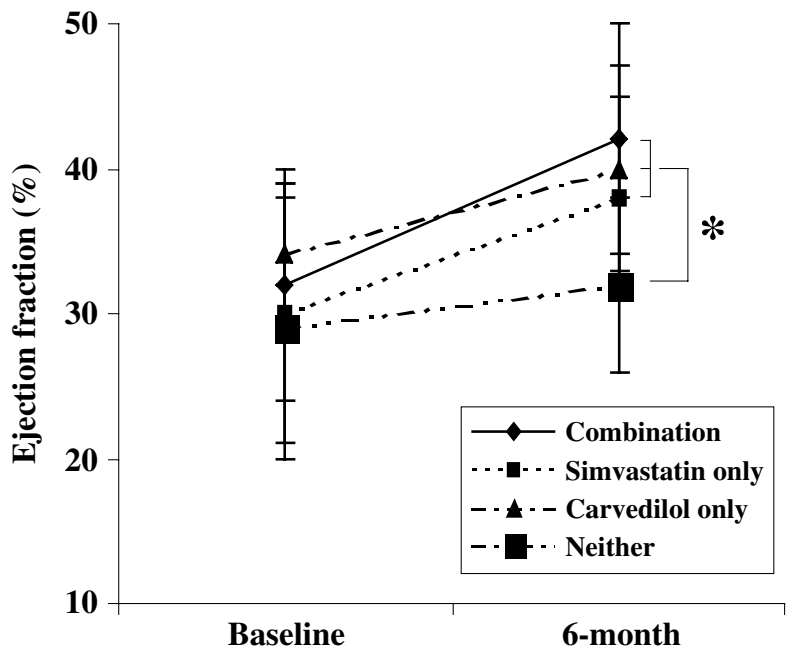

Fig 1. Changes in the left ventricular ejection fraction at 6 months after percutaneous coronary intervention. $* \mathrm{p}<0.05$ compared with neither treatment.

$77 \%$ relative risk reduction $(\mathrm{p}<0.001)$, simvastatin alone with a 59\% relative risk reduction $(\mathrm{p}<0.001)$, and carvedilol alone with a $50 \%$ relative risk reduction $(\mathrm{p}<0.001)$ of cardiac death compared with neither treatment. Combination therapy was associated with a 53\% relative risk reduction $(\mathrm{p}<0.001)$, simvastatin alone with a $44 \%$ relative risk reduction $(\mathrm{p}=0.001)$, and carvedilol alone with a $40 \%$ relative risk reduction $(\mathrm{p}=0.003)$ of 1 -year MACE compared with neither treatment (Fig 2).

\section{Independent Predictive Factors of MACE (Table 4)}

Variables tested included: age; diabetes mellitus; LVEF; angiographic minimal lumen diameter; hs-CRP level; monocyte count; treatment with simvastatin and carvedilol. In the multivariate analysis, the independent predictors of 1-year MACE were neither treatment, elevated hs-CRP 
Table 3 Major Adverse Cardiovascular Events at 1-Year After Percutaneous Coronary Intervention

\begin{tabular}{|c|c|c|c|c|}
\hline & \multicolumn{4}{|c|}{ Simvastatin use } \\
\hline & \multicolumn{2}{|c|}{$\begin{array}{c}(+) \\
\text { Carvedilol use }\end{array}$} & \multicolumn{2}{|c|}{$\begin{array}{c}(-) \\
\text { Carvedilol use }\end{array}$} \\
\hline & $\begin{array}{c}(+) \\
(n=160)\end{array}$ & $\begin{array}{c}(-) \\
(n=216)\end{array}$ & $\begin{array}{c}(+) \\
(n=242)\end{array}$ & $\begin{array}{c}(-) \\
(n=54)\end{array}$ \\
\hline Cardiac death & $6(4 \%) *$ & $15(7 \%) *$ & $20(8 \%) *$ & $9(17 \%)$ \\
\hline Cerebrovascular accident & $2(1 \%)$ & $3(1 \%)$ & $4(2 \%)$ & $2(4 \%)$ \\
\hline Repeat myocardial infarction & $4(3 \%)$ & $10(5 \%)$ & $11(5 \%)$ & $4(7 \%)$ \\
\hline Target lesion revascularization & $30(19 \%)$ & $43(20 \%)$ & $50(21 \%)$ & $13(24 \%)$ \\
\hline Event-free survival $(\%)$ & $125(78 \%) *$ & $160(74 \%) *$ & $175(72 \%)^{*}$ & $29(54 \%)$ \\
\hline
\end{tabular}

$*_{p}<0.05$ compared with neither treatment.

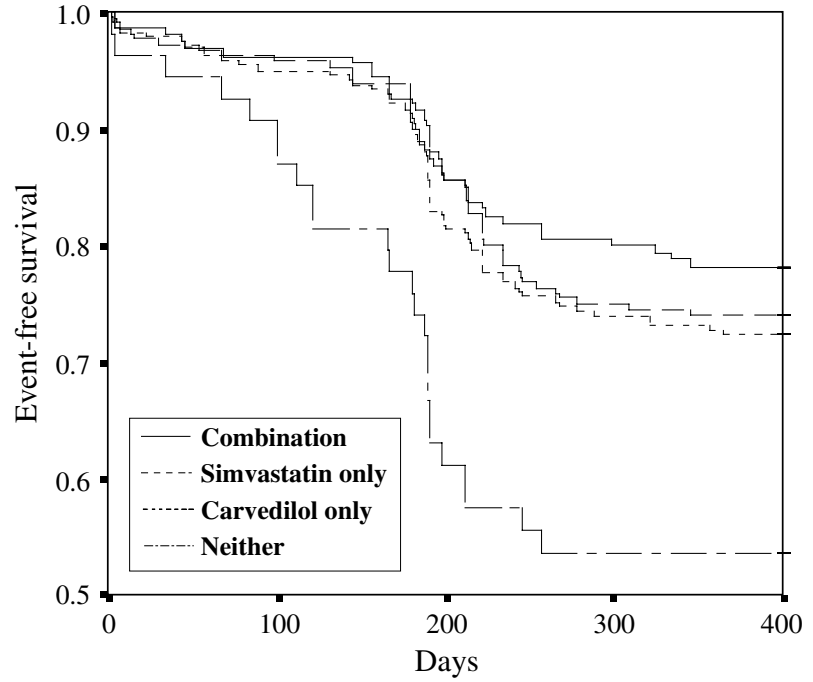

Fig 2. Kaplan-Meier survival curve.

$(\geq 0.5 \mathrm{mg} / \mathrm{dl})$, and old age ( $>70$ years).

\section{Discussion}

We have demonstrated that combination therapy with simvastatin and carvedilol decreased morbidity and mortality in patients with LV dysfunction complicating AMI who underwent PCI. Our results suggest that the combination has an additive beneficial effect on improving LV function and reducing morbidity and mortality.

We previously reported that simvastatin therapy lowered cardiac mortality in patients with ischemic HF complicating AMI who underwent PCI 19 Horwich et al ${ }^{7}$ studied the impact of statin therapy in a cohort of 551 patients with systolic HF (LVEF $\leq 40 \%)$. They showed that statin therapy was associated with improved survival without the necessity for urgent heart transplantation in both ischemic and non-ischemic HF patients and that statin therapy was an independent predictor of improved survival. Mozaffarian et $\mathrm{a}^{21}$ evaluated the effects of statin therapy in 1,153 patients with severe HF (LVEF <30\% and New York Heart Association (NYHA) class IIIB or IV symptoms) of ischemic and non-ischemic etiologies. They showed that statin therapy was associated with a $62 \%$ lower risk of death or 1 fewer death $/ 5$ patients taking statin therapy for 1 year after adjusting for age, gender, diabetes, smoking, HF etiology, LVEF, and NYHA class.

Statins inhibit mevalonate synthesis and effectively lowers LDL-cholesterol. Beyond lowering lipids, statins have favorable effects on vascular inflammation,22,23 endothelial function, ${ }^{24,25}$ and platelet adhesion and thrombosis ${ }^{26}$ The anti-atherothrombotic effects of statins clearly have potential benefit for patients with CAD-associated HF. Statins promote atherosclerotic plaque stabilization via inhibition of inflammatory macrophages, depletion of the lipid core, and strengthening of the fibrous cap. The mechanism for atherosclerotic plaque rupture and the impact of statins on plaque stabilization could reasonably be expected to be similar between patients with and without HF. Statins are now recognized as anti-inflammatory agents that downregulate inflammatory cytokines and CRP? ${ }^{27}-29$ Experimental studies in models of myocardial ischemia/reperfusion injury have demonstrated that statin treatment reduces the extent of myocardial necrosis, preserves myocardial viability, and results in improved ventricular function? 30

Carvedilol is known not only as a $\beta$ - and $\alpha$-adrenergicblocking drug but also as an antioxidant. The American Heart Association and American College of Cardiology (AHA/ACC) guidelines for secondary prevention of myocardial infarction (MI) recommend initiating $\beta$-adrenoceptor blockade in all post-MI patients and continuing the

Table 4 Multivariate Predictive Factors of Major Adverse Cardiovascular Events

\begin{tabular}{lccc}
\hline \hline & Odds ratio & $95 \% C I$ & $p$ value \\
\hline Neither treatment & 10.1 & $3.4-20.6$ & $<0.001$ \\
High sensitivity C-reactive protein $\geq 0.5 \mathrm{mg} / \mathrm{dl}$ & 6.2 & $2.9-12.3$ & 0.008 \\
Old age $(>70$ years) & 4.4 & $2.4-9.2$ & 0.014 \\
Diabetes mellitus & 1.4 & $0.8-1.8$ & 0.109 \\
LVEF & 0.8 & $0.6-1.4$ & 0.142 \\
MLD & 0.9 & $0.7-1.2$ & 0.328 \\
Monocyte count & 1.1 & $0.8-1.3$ & 0.394 \\
\hline
\end{tabular}

$C I$, confidence interval; $L V E F$, left ventricular ejection fraction; $M L D$, minimal lumen diameter. 
therapy indefinitely $3^{1}$ Beta-adrenoceptor antagonist therapy results in reduction of myocardial oxygen demand and is therefore also effective for the treatment of CAD. Carvedilol inhibits lipid peroxidation and prevents cardiac contractile dysfunction 32 and it inhibits mitochondrial oxygen consumption and superoxide production during calcium overload in isolated heart mitochondria, ${ }^{33}$ and it may reduce the oxidative stress level in the human failing myocardium.$^{10}$ Packer et al ${ }^{12}$ reported that in euvolemic patients with symptoms of HF at rest or on minimal exertion, the addition of carvedilol to conventional therapy ameliorated the severity of HF and reduced the risk of clinical deterioration, hospitalization, and other serious adverse clinical events. Because chronic $\beta$-adrenergic receptor signaling is the dominant cardiotoxic pathway in the failing heart, effective $\beta$-adrenergic receptor blockade by carvedilol is thought to be especially important ${ }^{34}$ Carvedilol also has an antiarrhythmic property. Experimentally, carvedilol reduces complex and repetitive ventricular ectopy induced by ischemia and reperfusion. In patients with atrial fibrillation and HF, carvedilol reduced mortality risk and improves LV function 35 In the Carvedilol Post-Infarct Survival Control in Left Ventricular Dysfunction (CAPRICORN) study36 carvedilol showed a powerful antiarrhythmic effect after AMI, even in patients already treated with an angiotensinconverting enzyme inhibitor. Carvedilol suppressed atrial as well as ventricular arrhythmias in these patients. Carvedilol also has salutary effects on progressive LV remodeling and functional deterioration 34,37

Despite the effectiveness of statin and carvedilol in altering subsequent cardiovascular mortality, studies have documented low treatment rates in patients with established CAD? Hognestad et $\mathrm{al}^{38}$ reported that early initiation of statin or $\beta$-blocker therapy was associated with improved event-free survival, and that the benefits of the combined treatment were additive. They demonstrated that the combination of statins and $\beta$-blockers was associated with a $48.3 \%$ relative risk reduction compared with neither treatment.

\section{Study Limitations}

A major limitation of this study is that it was not preplanned and was retrospective, so the patients were not randomized to receive simvastatin or carvedilol. Obviously, there was some selection bias among patients receiving simvastatin and carvedilol, which is evident from the difference in some of the baseline demograpthe 4 groups and hyperlipidemia was more frequently observed in the simvastatin-treated group than that in the no-simvastatintreated group. These findings support the need for prospective, randomized, blinded, placebo-controlled trials to determine whether the combination therapy will benefit patients with ischemic HF.

\section{Conclusions}

Our study results show that combination therapy with simvastatin and carvedilol was associated with a 77\% relative risk reduction of cardiac death and with a 53\% relative risk reduction of MACE compared with neither treatment. This suggests an additive beneficial effect of the combination therapy in patients with LV dysfunction complicating AMI who undergo PCI.

\section{Acknowledgments}

This study was supported by the grants of Cardiovascular Research Foundation Asia and Clinical Trial Center of Chonnam National University Hospital, Gwangju, Korea.

\section{References}

1. Thom T, Haase N, Rosamond W, Howard VJ, Rumsfeld J, Manolio $\mathrm{T}$, et al; American Heart Association Statistics Committee and Stroke Statistics Subcommittee. Heart disease and stroke statistics: 2006 update: A report from the American Heart Association Statistics Committee and Stroke Statistics Subcommittee. Circulation 2006; 113: e85-e151.

2. Fonarow GC. The role of in-hospital initiation of cardioprotective therapies to improve treatment rates and clinical outcomes. Rev Cardiovasc Med 2002; 3(Suppl 3): S2-S10.

3. The Scandinavian Simvastatin Survival Study Group. Randomised trial of cholesterol lowering in 4444 patients with coronary heart disease: The Scandinavian Simvastatin Survival Study (4S). Lancet 1994; 344: 1383-1389.

4. The Long-term Intervention with Pravastatin in Ischemic Disease (LIPID) Study Group. Prevention of cardiovascular events and death with pravastatin in patients with coronary heart disease and a broad range of initial cholesterol levels. N Engl J Med 1998; 339: 13491357.

5. The Heart Protection Study Collaborative Group. The MRC/BHF Heart Protection Study of cholesterol lowering with simvastatin in 20,536 high-risk individuals: A randomized placebo controlled trial. Lancet 2002; 360: 7-22.

6. Sacks FM, Pfeffer MA, Moye LA, Rouleau JL, Rutherford JD, Cole TG, et al. The effect of pravastatin on coronary events after myocardial infarction in patients with average cholesterol levels: Cholesterol and Recurrent Events Trial investigators. N Engl J Med 1996; 335: $1001-1009$.

7. Horwich TB, MacLellan WR, Fonarow GC. Statin therapy is associated with improved survival in ischemic and non-ischemic heart failure. J Am Coll Cardiol 2004; 43: 642-648.

8. Krum H, McMurray JJ. Statins and chronic heart failure: Do we need a large-scale outcome trial? J Am Coll Cardiol 2002; 39: 15671573 .

9. Horwich TB, Hamilton MA, Maclellan WR, Fonarow GC. Low serum total cholesterol is associated with marked increase in mortality in advanced heart failure. J Card Fail 2002; 8: 216-224.

10. Nakamura K, Kusano K, Nakamura Y, Kakishita M, Ohta K, Nagase $\mathrm{S}$, et al. Carvedilol decreases elevated oxidative stress in human failing myocardium. Circulation 2002; 105: 2867-2871.

11. Packer M, Coats AJ, Fowler MB, Katus HA, Krum H, Mohacsi P, et al; Carvedilol Prospective Randomized Cumulative Survival Study Group. Effect of carvedilol on survival in severe chronic heart failure. N Engl J Med 2001; 344: 1651-1658.

12. Packer M, Fowler MB, Roecker EB, Coats AJ, Katus HA, Krum H, et al; Carvedilol Prospective Randomized Cumulative Survival (COPERNICUS) Study Group. Effect of carvedilol on the morbidity of patients with severe chronic heart failure: Results of the carvedilol prospective randomized cumulative survival (COPERNICUS) study. Circulation 2002; 106: 2194-2199.

13. Australia/New Zealand Heart Failure Research Collaborative Group. Randomised, placebo-controlled trial of carvedilol in patients with congestive heart failure due to ischaemic heart disease. Lancet 1997; 349: $375-380$

14. Roberts WL, Moulton L, Law TC, Farrow G, Cooper-Anderson M, Savory J, et al. Evaluation of nine automated high-sensitivity C-reactive protein methods: Implications for clinical and epidemiological applications: Part 2. Clin Chem 2001; 47: 418-425.

15. Ellis SG, Vandormael MG, Cowley MJ, DiSciascio G, Deligonul U, Topol EJ, et al. Coronary morphological and clinical determinants of procedural outcome with angioplasty for multivessel disease. Circulation 1990; 82: 1193-1202.

16. Moussa I, Di Mario C, Reimers B, Akiyama T, Tobis J, Colombo A. Subacute stent thrombosis in the era of intravascular ultrasoundguided coronary stenting without anticoagulation: Frequency, predictors and clinical outcome. J Am Coll Cardiol 1997; 29: 6-12.

17. Hong YJ, Jeong MH, Lim SY, Lee SR, Kim KH, Sohn IS, et al. Elevated preprocedural high-sensitivity C-reactive protein levels are associated with neointimal hyperplasia and restenosis development after successful coronary artery stenting. Circ $J$ 2005; 69: $1477-$ 1483.

18. Foussas SG, Zairis MN, Lyras AG, Patsourakos NG, Tsirimpis VG, Katsaros K, et al. Early prognostic usefulness of C-reactive protein 
added to the Thrombolysis In Myocardial Infarction risk score in acute coronary syndromes. Am J Cardiol 2005; 96: 533-537.

19. Hong YJ, Jeong MH, Hyun DW, Hur SH, Kim KB, Kim W, et al. Prognostic significance of simvastatin therapy in patients with ischemic heart failure who underwent percutaneous coronary intervention for acute myocardial infarction. Am J Cardiol 2005; 95: $619-622$.

20. Ohno J, Watanabe E, Toyama J, Kawamura T, Ohno M, Kodama I. Risk stratification and survival in post myocardial infarction patients: A large prospective and multicenter study in Japan. Int J Cardiol 2004; 93: 263-268.

21. Mozaffarian D, Nye R, Levy WC. Statin therapy is associated with lower mortality among patients with severe heart failure. Am J Cardiol 2004; 93: 1124-1129.

22. Strandberg TE, Vanhanen H, Tikkanen MJ. Effect of statins on Creactive protein in patients with coronary artery disease. Lancet 1999; 353: $118-119$.

23. Ridker PM, Rifai N, Pfeffer MA, Sacks FM, Moye LA, Goldman S, et al. Inflammation, pravastatin, and the risk of coronary events after myocardial infarction in patients with average cholesterol levels: Cholesterol and Recurrent Events (CARE) Investigators. Circulation 1998; 98: 839-844

24. Dupuis J, Tardif JC, Cernacek P, Theroux P. Cholesterol reduction rapidly improves endothelial function after acute coronary syndromes: The RECIFE (reduction of cholesterol in ischemia and function of the endothelium) trial. Circulation 1999; 99: 3227 3233.

25. Takayama T, Wada A, Tsutamoto T, Ohnishi M, Fujii M, Isono T, et al. Contribution of vascular $\mathrm{NAD}(\mathrm{P}) \mathrm{H}$ oxidase to endothelial dysfunction in heart failure and the therapeutic effects of HMG-CoA reductase inhibitor. Circ J 2004; 68: 1067-1075.

26. Lacoste L, Lam JY, Hung J. Hyperlipidemia and coronary disease Correction of the increased thrombogenic potential with cholesterol reduction. Circulation 1995; 92: $3172-3177$.

27. Lefer DJ. Statins as potent anti-inflammatory drugs. Circulation 2002; 106: 2041 - 2042 .

28. Rosenson RS, Tangney CC, Casey LC. Inhibition of proinflammatory cytokine production by pravastatin. Lancet 1999; 353: 983 984

29. Ridker PM, Rifai N, Pfeffer MA, Sacks F, Braunwald E. Long-term effects of pravastatin and plasma concentration of C-reactive protein. Circulation 1999; 100: 230-235.

30. Remme WJ. Overview of the relationship between ischemia and congestive heart failure. Clin Cardiol 2000; 23(Suppl 4): IV4-IV8.

31. Antman EM, Anbe DT, Armstrong PW, Bates ER, Green LA, Hand $\mathrm{M}$, et al; American College of Cardiology; American Heart Association Task Force on Practice Guidelines. ACC/AHA guidelines for the management of patients with ST-elevation myocardial infarction: Executive summary: A report of the American College of Cardiology/American Heart Association Task Force on Practice Guidelines (Writing Committee to Revise the 1999 Guidelines for the Management of Patients With Acute Myocardial Infarction). Circulation 2004; 110: $588-636$.

32. Flesch M, Maack C, Cremers B, Baumer AT, Sudkamp M, Bohm M. Effect of beta-blockers on free radical-induced cardiac contractile dysfunction. Circulation 1999; 100: 346-353.

33. Kametani R, Miura T, Harada N, Shibuya M, Wang R, Tan H, et al. Carvedilol inhibits mitochondrial oxygen consumption and superoxide production during calcium overload in isolated heart mitochondria. Circ J 2006; 70: 321-326.

34. Bristow MR. Beta-adrenergic receptor blockade in chronic heart failure. Circulation 2000; 101: 558-569.

35. Naccarelli GV, Lukas MA. Carvedilol's antiarrhythmic properties: Therapeutic implications in patients with left ventricular dysfunction. Clin Cardiol 2005; 28: 165-173.

36. McMurray J, Kober L, Robertson M, Dargie H, Colucci W, LopezSendon J, et al. Antiarrhythmic effect of carvedilol after acute myocardial infarction: Results of the Carvedilol Post-Infarct Survival Control in Left Ventricular Dysfunction (CAPRICORN) trial. J Am Coll Cardiol 2005; 45: 525-530.

37. Yang YJ, Tang YD, Ruan YM, Zhang P, Zhou YW, Wang PH, et al. Comparative effects of carvedilol and losartan alone and in combination for preventing left ventricular remodeling after acute myocardial infarction in rats. Circ J 2003; 67: 159-162.

38. Hognestad A, Dickstein K, Myhre E, Snapinn S, Kjekshus J; OPTIMAAL Investigators. Effect of combined statin and betablocker treatment on one-year morbidity and mortality after acute myocardial infarction associated with heart failure. Am J Cardiol 2004; 93: 603-606. 